\title{
Post-curing conversion kinetics as functions of the irradiation time and increment thickness
}

\author{
Nicola SCOTTI ${ }^{1}$, Alberto VENTURELLO ${ }^{2}$, Francesco Andrea Coero BORGA ${ }^{3}$, Damiano PASQUALINI ${ }^{4}$, Davide Salvatore \\ PAOLINO $^{5}$, Francesco GEOBALDO ${ }^{6}$, Elio BERUTTI ${ }^{7}$
}

\author{
1- DDS, Assistant Professor, Department of Surgical Sciences, Dental School Lingotto, University of Turin, Turin, Italy. \\ 2- PhD, Department of Material Science and Chemical Engineering, Politecnico di Torino, Turin, Italy. \\ 3- DDS, Department of Surgical Sciences, Dental School Lingotto, University of Turin, Turin, Italy \\ 4- DDS, Assistant Professor, Department of Surgical Sciences, Dental School of Lingotto, University of Turin, Turin, Italy. \\ 5- PhD, Assistant Professor, Department of Mechanics, Politecnico di Torino, Turin, Italy. \\ 6- PhD, Associate Professor, Department of Material Science and Chemical Engineering, Politecnico di Torino, Turin, Italy. \\ 7- MD, DDS, Dean and Professor, Department of Surgical Sciences, Dental School Lingotto, University of Turin, Turin, Italy.
}

Corresponding address: Dr. Nicola Scotti - Via Nizza, 230 - 10125 - Torino - Italy - Phone: +39(0)11/6331568 - Fax: +39(0)11/6690602 - e-mail: nicola. scotti@unito.it

Received: May 15, 2012 - Modification: January 3, 2013 - Accepted: February 6, 2013

\section{ABSTRACT}

\begin{abstract}
bjective: This study evaluated the variation of conversion degree (DC) in the 12 hours following initial photoactivation of a low-shrinkage composite resin (Venus Diamond). Material and Methods: The conversion degree was monitored for 12 hours using Attenuated Total Reflection (ATR) F-TIR Spectroscopy. The composite was placed in 1 or $2 \mathrm{~mm}$ rings and cured for 10 or 20 seconds with a LED lamp. ATR spectra were acquired from the bottom surface of each sample immediately after the initial photoactivation $(P=0), 30$ minutes $(P=0.5)$ and 12 hours after photoactivation $(P=12)$ in order to obtain the DC progression during the post-curing period. Interactions between thickness ( $T$ ), irradiation time (I) and post-curing $(P)$ on the DC were calculated through ANOVA testing. Results: All the first order interactions were statistically significant, with the exception of the T-P interaction. Furthermore, the shift from $\mathrm{P}=0$ to $\mathrm{P}=0.5$ had a statistically higher influence than the shift from $P=0.5$ to $P=12$. The post-curing period played a fundamental role in reaching higher DC values with the low-shrinkage composite resin tested in this study. Moreover, both the irradiation time and the composite thickness strongly influenced the DC. Conclusions: Increased irradiation time may be useful in obtaining a high conversion degree (DC) with a low-shrinkage nano-hybrid composite resin, particularly with $2 \mathrm{~mm}$ composite layers.
\end{abstract}

Key words: Post-curing. Thickness. Irradiation time. LED. Low-shrinkage composite.

\section{INTRODUCTION}

Light-cured composite resins are widely used in restorative dentistry due to their aesthetic advantage, ease of handling and their capability to bond with dental structures ${ }^{15}$. These materials contain a blend of hard inorganic particles of different properties, bound together by an organic resin matrix. The composite resins are cured with a free radical polymerization mechanism. The photochemical initiation is obtained by a light source of appropriate wavelength. The polymerization of composite resins occurs through the formation of a polymer network that is always correlated to a volumetric contraction between $1.5 \%$ and
$5 \%{ }^{13,17}$. The immediate consequence of composite shrinkage is a competition between the contraction forces and the strength of the bond to the dental structures. This generates a stress along the cavity walls during the polymerization process ${ }^{6}$. Several studies that have investigated composite shrinkage conclude that an important shrinkage occurs during visible light curing of the resin matrix due to radical polymerization ${ }^{5}$. Shrinkage was also shown to occur during the 24 hours after photoactivation ${ }^{32}$ : this latter phenomenon is usually called "postpolymerization"21. The temperature at which the composite passes from a vitreous phase, that is reached during photoactivation, to a liquid phase, is above the environment temperature $\left(25^{\circ} \mathrm{C}\right)$ or 
the oral temperature $\left(36.2^{\circ} \mathrm{C}\right)$. Therefore, following vitrification of the material (post-gel phase), all the free radicals and molecules containing double bonds that have not reacted remain entrapped in the matrix without the ability to flow. Moreover, it has been observed that, owing to photoactivation, once the composite material has reached its vitreous form, some "free spaces" remain. After the exothermic reaction of the polymerization, the composite resin reduces in temperature to that of the oral cavity. A relaxation process follows which is necessary for the structure to reach a more stable crystalline form and this is associated with a partial reduction of the "free spaces" present within the polymer network. This physical phenomenon is responsible for the spontaneous approach of free radicals to the residual double bonds. These may react, allowing the composite material to further increase the conversion degree $(D C)^{33}$. A previous study conducted by Trouffier-Boutry, et al. ${ }^{32}$ (2006) concluded that, during the 24 hours following polymerization, the DC of composites resins do not increase significantly (approximately $2 \%$ ). Other studies have shown that a continuous increase of contraction stress occurs for different periods of time after the photoactivation process ${ }^{20,27}$. The increase of stress following light exposure is associated with an additional polymerization and with the occurrence of thermal shrinkage in the restorative composite $2,14,15,27$. These contraction stresses, which occur in the composite resin during polymerization, could generate many clinical problems, such as: cohesive fractures resulting in microcracks, debonding at the filler particle/resin interface, adhesive fractures that may lead to marginal gap formation, marginal discoloration, post-operative sensitivity, and secondary caries ${ }^{8}$. The clinical consequences of polymerization shrinkage represent the main reason for the premature replacement of composite resin restorations ${ }^{11}$. Several clinical solutions have been proposed to compensate for volumetric composite contraction and contraction stress, such as different layer-by-layer filling techniques ${ }^{34}$ or incremental curing protocols ${ }^{1}$. In recent years the most innovative attempt at compensating polymerization shrinkage has been the introduction of composite resins with a reduced volumetric contraction. Within low-shrinkage composite resins, a previous study suggested that the Venus Diamond has a strongly reduced contraction stress value ${ }^{24}$. However, no study has been conducted on the conversion degree kinetics of low-shrinkage composite resins. For this reason, the analysis of the photoactivation kinetics of the Venus Diamond must be studied.

The aim of this in vitro study was to evaluate the variation of DC in the 12 hours following photoactivation of a low-shrinkage composite resin. The null hypothesis is that the modification of the DC during the post-curing period is significantly affected by both the composite thickness and the irradiation time.

\section{MATERIAL AND METHODS}

\section{Specimen preparation}

A commercially available nano-hybrid composite resin (Venus Diamond, Heraeus Kultzer, Hanau, Germany), shade A2, was selected for this study (Table 1). Aluminium rings, all of $10 \mathrm{~mm}$ diameter, with different thickness ( $1 \mathrm{~mm}$ or $2 \mathrm{~mm}$ ), were placed, one at a time, inside the Attenuated Total Reflection (ATR) machine (Eqinox 55, Bruker Optics S.p.A.) so that the position of the ATR diamond crystal always corresponded with the centre of the aluminium ring. A total of 32 samples were prepared for in vitro study, 16 for each thickness (group A: $1 \mathrm{~mm}$ thickness; group B: $2 \mathrm{~mm}$ thickness). The composite resin was bulk-placed inside the aluminium ring and pressed flat against glass to obtain a uniform thickness. It was covered with a $1 \mu \mathrm{m}$ film of cellulose triacetate to ensure uniform polymerization. The lamp tip was placed in contact with the triacetate and the photoactivation was

Table 1- Mean DC ( \pm standard deviation) obtained in the different groups of $P=0, P=0.5$ and $P=12$, and the percentage increase of DC

\begin{tabular}{|c|c|c|c|c|c|c|c|c|}
\hline GROUP & SUBGROUP & $\begin{array}{l}\text { Irradiation } \\
\text { Time }\end{array}$ & $\begin{array}{c}\text { Sample } \\
\text { Thickness }\end{array}$ & $P=0$ & $P=0.5$ & $P=12$ & $\begin{array}{c}\text { "DC } \\
\text { increase } \\
\text { (P0-P0.5)" }\end{array}$ & $\begin{array}{c}\text { "DC } \\
\text { increase } \\
\text { (P0.5-P12)" }\end{array}$ \\
\hline \multirow[t]{2}{*}{$\begin{array}{c}A \\
(n=16)\end{array}$} & $1(n=8)$ & $10 \mathrm{sec}$ & $1 \mathrm{~mm}$ & $\begin{array}{l}31.773 \% \\
( \pm 1.732)\end{array}$ & $\begin{array}{l}44.586 \% \\
( \pm 1.200)\end{array}$ & $\begin{array}{l}52.377 \% \\
( \pm 1.906)\end{array}$ & $40.33 \%$ & $17.47 \%$ \\
\hline & $2(n=8)$ & $20 \mathrm{sec}$ & $1 \mathrm{~mm}$ & $\begin{array}{l}40.518 \% \\
( \pm 1.378)\end{array}$ & $\begin{array}{l}47.808 \% \\
( \pm 1.220)\end{array}$ & $\begin{array}{l}54.172 \% \\
( \pm 1.933)\end{array}$ & $17.99 \%$ & $13.31 \%$ \\
\hline \multirow[t]{2}{*}{$\begin{array}{c}B \\
(n=16)\end{array}$} & $1(n=8)$ & $10 \mathrm{sec}$ & $2 \mathrm{~mm}$ & $\begin{array}{l}24.036 \% \\
( \pm 4.493)\end{array}$ & $\begin{array}{l}36.196 \% \\
( \pm 5.802)\end{array}$ & $\begin{array}{l}43.158 \% \\
( \pm 7.122)\end{array}$ & $50.59 \%$ & $19.23 \%$ \\
\hline & $2(n=8)$ & $20 \mathrm{sec}$ & $2 \mathrm{~mm}$ & $\begin{array}{l}38.592 \% \\
( \pm 2.642)\end{array}$ & $\begin{array}{l}45.281 \% \\
( \pm 1.981)\end{array}$ & $\begin{array}{l}52.595 \% \\
( \pm 2.137)\end{array}$ & $17.33 \%$ & $16.15 \%$ \\
\hline
\end{tabular}


performed.

\section{Curing protocol}

The curing device employed in this study was a light emitting diode (LED) light (Translux Power Blue, Heareus Kultzer, Hanau, Germany). Prior to the study, the output of the curing unit was verified, with a radiometer test (Sybron-Kerr). The same level of irradiance was used for all specimens (as measured at the surface of the specimen, $1000 \mathrm{~mW} / \mathrm{cm}^{2}$ ). Sixteen samples, eight for each thickness, were cured for 10 seconds (subgroups 1 ), while the remaining 16 were cured for 20 seconds (subgroups 2). All experiments were performed at room temperature $\left(22 \pm 1^{\circ} \mathrm{C}\right)$.

\section{Experimental data collection}

Methacrylate monomer conversion in the resin was accomplished before polymerization by Attenuated Total Reflection Fourier Transform Infrared (ATR F-TIR)(Eqinox 55, Bruker Optics S.p.A.), equipped with a MCT detector and ATR sample compartment containing a diamond crystal, under the following conditions: range $4000-600 \mathrm{~cm}^{-}$ 1 , resolution $2 \mathrm{~cm}^{-1}, 32$ scans at $25^{\circ} \mathrm{C} \pm 1^{\circ} \mathrm{C}$. Each sample was submitted to the curing protocol and the DC at the bottom surface of the sample was measured.

The infrared (IR) spectra presented a peak at $1716 \mathrm{~cm}^{-1}$ (carbon oxygen double bond stretching), a peak at $1636 \mathrm{~cm}^{-1}$ (carbon double bond), and a peak at $1532 \mathrm{~cm}^{-1}$ (aromatic double bond). The intensity of each peak was calculated after an appropriate baseline correction and the polymerization rate was calculated using the follow equation:

PR $(\%)=\left(1-\left(I^{\circ} 636 / I 1532\right) /\left(I^{\circ} 1636 / I^{\circ} 1532\right)\right)$ $\times 100$

$\mathrm{PR}$, polymerization rate; $\mathrm{I}$, intensity of the peak

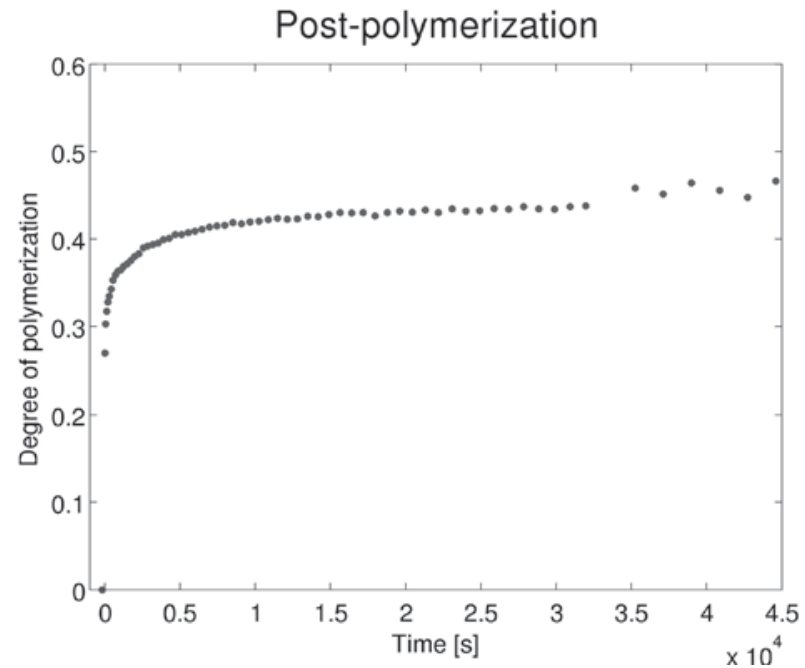

Figure 1- Conversion degree (DC) progression during the 12-hour post-curing period acquired through F-TIR analysis in the cured resin; $\mathrm{I}^{\circ}$, intensity of the peak in the non-cured resin.

ATR spectra were acquired immediately after photoactivation $(P=0), 30$ minutes after photopolymerization $(P=0.5)$ and 12 hours after photoactivation $(P=12)$ in order to obtain the $D C$ progression during the post-curing period (Figure 1). The sample was not removed from the ATR machine to ensure better reproducibility of the test.

\section{Statistical analysis}

In order to evaluate the interactions of thickness $(T)$, irradiation time (I) and post-curing $(P)$, and their influence on the DC of the tested composite resin, an analysis of variance (ANOVA) was performed. Statistical analyses were carried out using SW Minitab v.15 (Minitab Inc., State College, PA, USA) and a $p$ value of $<0.05$ was considered statistically significant.

\section{RESULTS}

The mean DC ( \pm standard deviation [SD]) obtained in the different groups of $P=0, P=0.5$ and $P=12$, and the percentage increase of $D C$ is summarized in Table 2. Percentage increase expressed the $D C$ values increase between $P=0$, $\mathrm{P}=0.5$ and $\mathrm{P}=12$.

Table 2- Statistical significance $(p)$ of the interactions of thickness $(T)$, irradiation time $(I)$ and post-curing $(P)$ tested in the investigation

\begin{tabular}{cc}
\hline Source & $\mathbf{p}$ \\
\hline $\mathrm{I}$ & $<.0005$ \\
$\mathrm{~T}$ & $<.0005$ \\
$\mathrm{P}$ & $<.0005$ \\
Interaction I-T & $<.0005$ \\
Interaction I-P & $<.0005$ \\
Interaction T-P & 0.901 \\
\hline Interaction I-T-P & 0.842 \\
\hline
\end{tabular}

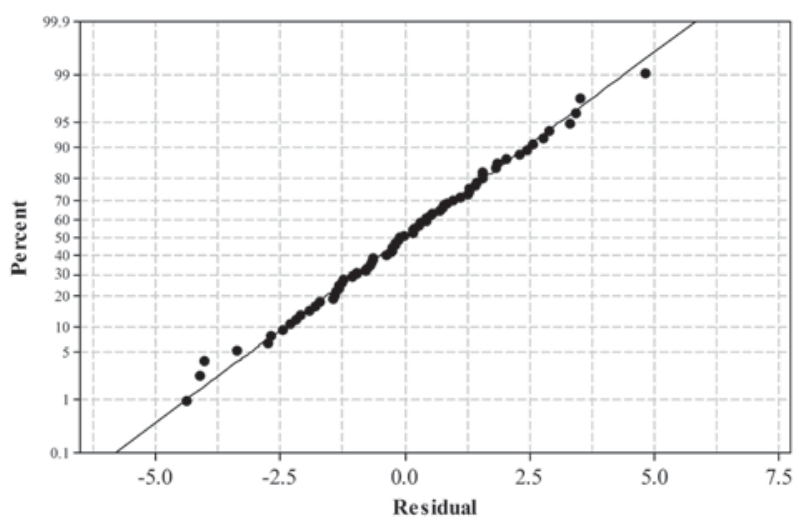

Figure 2- Normal probability plot of residuals 


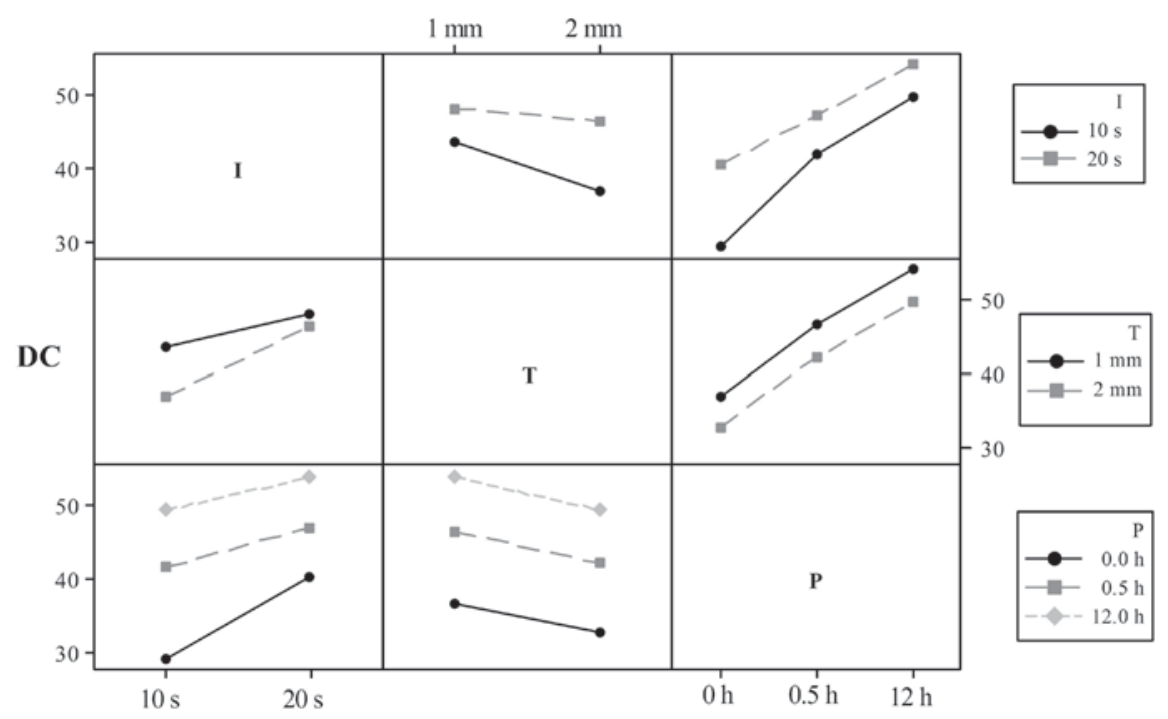

Figure 3- The interaction plot shows the first order interactions between irradiation time (I), thickness (T) and post-curing conversion degree (DC) (P). When lines are parallel, no statistically significance was found. The variation in the line slope suggests that these interactions significantly influenced variation in DC. A significant variation of the line slope was noticed relative to the intersection between I and T (I-T interaction) and between I and P (I-P interaction). In particular, as for the $\mathrm{I}-\mathrm{P}$ interaction, a significant slope change was noticed only in the shift from $0.0 \mathrm{~h}$ to $0.5 \mathrm{~h}$ level

The residuals followed a normal distribution (Figure 2). With the exception of the T-P interaction, all the first order interactions were statistically significant (Figure 3 ). The results of the ANOVA test showed that $I(p<.0005), T(p<.0005)$ and $P$ $(p<.0005)$ significantly influenced the $D C$ response. In order to analyze the influence of the $P$ factor alone, two further ANOVA tests were conducted. When the $P$ level corresponding to 12 hours was eliminated, the $P$ factor significantly influenced the shift from $P=0$ to $P=0.5(p<0.0005)$. In the second ANOVA test, the $P$ level corresponding to $P=0$ was eliminated and the $P$ factor was again shown to significantly influence the shift from $P=0.5$ to $P=12$ $(p<0.0005)$. Together, these results demonstrate that, during the shift from $P=0$ to $P=0.5$, and from $P=0.5$ to $P=12$, there was a statistically significant change in $D C$ value. The $D C$ values obtained in samples $A 1$ and $B 1$, show that the shift from $P=0$ to $P=0.5$ has a greater influence than the shift from $P=0.5$ to $P=12$ in achieving high values of $D C$ (Table 1, Figure 3).

\section{DISCUSSION}

Since only the irradiation time showed a significant interaction with the post-curing behavior of the DC, the results of this in vitro study lends partial support to the null hypothesis.

No previous studies described a correlation between curing time, composite thickness and conversion degree evolution overtime.

This in vitro study was designed to test a lowshrinkage nano-hybrid composite resin, thus the Venus Diamond was selected for this study. This product is constituted of a resin based on TCD-DI-HEA [bis-(acryloyloxymethyl)tricycle (5.2.1.0.sup.2,6) decane] and UDMA (urethanedimethacrylate). This composite already showed excellent shrinkage stress behavior. In fact it has been recently demonstrated by Marchesi, et al. ${ }^{24}$ (2010) that Venus Diamond showed a lower contraction stress when compared with both silorane-based and dymethacrilate-based restorative materials ${ }^{24}$. However, no studies on the DC behavior during the post-polymerization period of this composite resin have ever been conducted.

The degree of conversion of the composite resin was assessed through FTIR analysis, a reliable and sensitive method of evaluation $7,26,29,32$. The determination of the degree of conversion was carried out on the non-irradiated surface of specimens in order to consider the sample thickness. The evaluation of the conversion degree at the bottom surface of composite samples is clinically relevant because it simulates what happens at the bottom of adhesive restorations, as pointed out by D'Alpino, et al. ${ }^{9}$ (2007). The degree of conversion was measured immediately after light irradiance $(P=0)$ and after 30 minutes $(P=0.5)$ and 12 hours $(P=12)$ in order to reflect the clinical practice where the dentist may require the restoration to be sufficiently cured to permit an immediate masticatory loading, and because the mechanical properties of the composite resin are directly influenced by the DC obtained through photoactivation ${ }^{16,23}$. After the initial curing, samples were left in the ATR machine for the following 12 hours in order to evaluate the DC progression, which represent an innovative way to study DC kinetics. It has been documented that the DC progression 
increases during the post-curing phase ${ }^{28,32}$. The DC obtained immediately after irradiation $(P=0), 30$ minutes after irradiation $(P=0.5)$ and 12 hours after irradiation $(P=12)$ were considered in this study.

The results of this in vitro study indicated that both the irradiation time and the composite thickness were significantly correlated to the DC. This was true in group $A$ and in group $B$. If evaluated immediately after the photoactivation $(P=0)$, the increase of irradiation time from 10 to 20 seconds produced a significant increase of the DC. Moreover, the DC obtained with $1 \mathrm{~mm}$ samples was significantly higher than for $2 \mathrm{~mm}$ samples. These results concur with those obtained from previous studies ${ }^{11,12,20-22}$. The greatest amount of energy density supplied by the LED lamp to the composite resin during 20 seconds of irradiation immediately resulted in a faster release of free radicals and, consequently, a greater opening of the double bonds within the methacrylic groups and a higher DC of the material. Previous studies argued that the degree of conversion and, therefore, the polymerization depth, are influenced by the amount of energy emitted to the composite, which is derived from both the irradiation time and the power of the curing device ${ }^{10}$. However, it is well known that the high power associated with short irradiation times reduce the DC of the composite resins due to limitations in the mobility of reactive groups imposed by the rapid formation of a polymeric chain ${ }^{30}$. Consequently, an increase in the irradiation time positively influenced the DC at the bottom surface of the samples. Gritsch, et al. ${ }^{18}$ (2008) demonstrated that an increased irradiation time associated with low power improved the depth of cure due to a delay in the formation of rigid grid links between the polymer chains ${ }^{18}$.

This study indicates that a reduced irradiation time is associated with an increased composite thickness. This was shown by group B1 where the lowest $D C$ was observed in $P=0$, as in $P=12$. This result supports previous studies which demonstrate that the DC of a composite resin is influenced by the interaction between composite thickness and irradiation time $3,4,10,21,25,31$. The increase of composite thickness required longer irradiation times in order to obtain a comparable DC. This phenomenon can be explained by the effect of light energy incident on the surface of a material, during the attempt to cross it, by a coefficient of attenuation proportional to the physical characteristics of the material itself (Lambert Law).

This study evaluated the modification of the DC during the post-curing period. The statistical analysis showed that only the interaction between the irradiation time (I) and post-curing ( $P$ ) was strongly significant (Table 2 ). The data obtained in this study showed that in both group A1 and group $B 1$ the DC strongly increased between $P=0$ and
$P=12$, until approaching the $D C$ registered in group $A 2$ at $P=12$. In $P=12$, the $D C$ of groups $A 1$ and $A 2$, which were always measured on the non-irradiated surface of the samples, did not show any statistically significant difference. Furthermore, the most significant $D C$ increase was registered between $P=0$ and $P=0.5(+40.33 \%)$, and this continued between $\mathrm{P}=0.5$ and $\mathrm{P}=12(+17.47 \%)$. Despite an absence of research evaluating the $\mathrm{DC}$ progression during the post-curing period on the non-irradiated surface of a low-shrinkage composite resin, the results achieved in this in vitro study can be explained by the ability of the tested composite to receive and capture energy during irradiation and to release it slowly during the next 12 hours. Therefore, it can be assumed that the energy released to the composite in the first 10 seconds of polymerization was enough to open a greater quantity of double bonds within the methacrylic groups during the 12hour post-curing period, and hence determined a comparable final DC between groups $A 1$ and $A 2^{34}$. This was despite a reduced activation of free radicals and, consequently, a reduced $\mathrm{DC}$ in $\mathrm{P}=0$. In groups $B$, the DC behaved in a similar manner to groups A during the post-curing period. The statistical analysis showed a non-significant interaction between thickness $(T)$ and post-curing $(P)$. The $D C$ increased to a greater extent between $P=0$ and $\mathrm{P}=0.5$ in group $\mathrm{B} 1(+50.59 \%)$ than in group $\mathrm{B} 2$ $(+17.33 \%)$, as illustrated in the $1 \mathrm{~mm}$ samples. However, the difference in $\mathrm{DC}$ registered in $\mathrm{P}=0$, remained almost unchanged following 12 hours of post-polymerization. It has been shown that the DC of the composite resin depends on the energy density released to the material. Hence, in order to achieve the same degree of conversion in $2 \mathrm{~mm}$ samples, an increased energy density is necessary ${ }^{19}$. $A$ recent study ${ }^{24}$ underlined that, according to the contraction stress curves, the Venus Diamond cures very slowly. This would contribute to its reduced stress, despite its high filler loading (64\% volume). The TCD monomer contained in the Venus Diamond may cure slowly due to the presence of large rings accounting for steric hindrance during curing. For this reason, post-curing analysis of other composite resins is necessary.

When employing the tested material in clinical practice, it may be appropriate to adopt a layerby-layer stratification technique with a composite apposition $1 \mathrm{~mm}$ thick and 10 seconds of curing with a LED lamp. The DC after the post-curing period is close to that obtained with 20 seconds of curing. In contrast, 20 seconds of irradiation is necessary when using composite layers of $2 \mathrm{~mm}$ thickness. Furthermore, regardless of the thickness and the irradiation time, the tested composite showed a consistent increase of DC during the post-curing period. For this reason it appears that the Venus 
Diamond reached ideal mechanical properties after the 12-hour post-curing period. This provides the rationale for further investigation of the mechanical properties during the post-curing period.

\section{CONCLUSIONS}

The results obtained in this in vitro investigation lend partial support to the null hypothesis since the DC of the tested nano-hybrid composite show an important increase during the post-curing period. Moreover, the DC registered at the non-irradiated surface in $P=0$ was significantly related to both the material thickness and the irradiation time.

\section{REFERENCES}

1- Alonso RC, Cunha LG, Correr GM, Cunha Brandt W, Correr-Sobrinho L, Sinhoreti MA. Relationship between bond strength and marginal and internal adaptation of composite restorations photocured by different methods. Acta Odontol Scand 2006;64(5):306-13.

2- Aravamudhan K, Floyd CJ, Rakowski D, Flaim G, Dickens SH, Eichmiller $\mathrm{FC}$, et al. Light-emitting diode curing light irradiance and polymerization of resin-based composite. J Am Dent Assoc. 2006;137:213-23.

3- Bala O, Olmez A, Kalayci S. Effect of LED and halogen light curing on polymerization of resin-based composites. J Oral Rehabil. 2005;32:134-40.

4- Bouschlicher MR, Rueggeberg FA, Wilson BM. Correlation of bottom-to-top surface microhardness and conversion ratios for a variety of composite resin compositions. Oper Dent. 2004;29:698704.

5- Braga RR, Ballester RY, Ferracane JL. Factors involved in the development of polymerization shrinkage stress in composite resins: a systematic review. Dent Mater. 2005;21:962-70.

6- Choi KK, Condon JR, Ferracane JL. The effects of adhesive thickness on polymerization contraction stress of composite. J Dent Res. 2000;79:812-7.

7- Conti C, Giorgini E, Landi L, Putignano A, Tosi G. Spectroscopic and mechanical properties of dental composite resins cured with different light sources. J Molecular Struct. 2005;744-7:641-6.

8- Correr AB, Sinhoreti MA, Correr-Sobrinho L, Tango RN, Schneider LF, Consani S. Effect of the increase of energy density on Knoop hardness of dental composites light-cured by conventional QTH, LED and xenon plasma arc. Braz Dent J. 2005;16:218-24. 9- D'Alpino PH, Svizero NR, Pereira JC, Rueggeberg FA, Carvalho RM, Pashley DH. Influence of light-curing sources on polymerization reaction kinetics of a restorative system. Am J Dent. 2007;20:46-52.

10- Davidson CL, Feilzer AJ. Polymerization shrinkage and polymerization shrinkage stress in polymer-based restoratives. J Dent. 1997; 25:435-40.

11- Dewaele M, Truffier-Boutry D, Devaux J, Leloup G. Volume contraction in photocured dental resins: the shrinkage-conversion relationship revisited. Dent Mater. 2006;22:359-65.

12- Fan PL, Schumacher RM, Azzolin K, Geary R, Eichmiller FC. Curing-light intensity and depth of cure of resin-based composites tested according to international standards. J Am Dent Assoc. 2002;133:429-34.

13- Feilzer AJ, De Gee AJ, Davidson CL. Curing contraction of composites and glass-ionomer cements. J Prosthet Dent. 1988;59:297-300.

14- Ferracane JL. Correlation between hardness and degree of conversion during the setting reaction of unfilled dental restorative resins. Dent Mater. 1985;1:11-4.
15- Ferracane JL. Composite resin - state of the art. Dent Mater. 2011;27:29-38.

16- Ferracane JL, Greener EH. The effect of resin formulation on the degree of conversion and mechanical properties of dental restorative resins J Biomed Mater Res. 1986;20:121-31.

17- Gonçalves F, Pfeifer CS, Ferracane JL, Braga RR. Contraction stress determinants in dimetacrylate composites. J Dent Res. 2008;87:367-71.

18- Gritsch K, Souvannasot S, Schembri C, Farge P, Grosgogeat B. Influence of light energy and power density on the microhardness of two nano-hybrid composites. Eur J Oral Sci. 2008;116:77-82. 19- Halvorson RH, Erickson RL, Davidson CL. An energy conversion relationship predictive of conversion profiles and depth of cure for resin-based composite. Oper Dent. 2003;28:307-14.

20- Inoue K, Hayashi I. Residual monomer (Bis-GMA) of composite resins. J Oral Rehabil. 1982;9:493-7.

21- Leung RL, Fan PL, Johnston WM. Post-irradiation polymerization of visible light-activated composite resin. J Dent Res. 1983;62 363-5.

22- Lindberg A, Peutzfeldt A, van Dijken JW. Effect of power density of curing unit, exposure duration, and light guide distance on composite depth of cure. Clin Oral Invest. 2005;9:71-6.

23- López-Suevos F, Dickens SH. Degree of cure and fracture properties of experimental acid-resin modified composites under wet and dry conditions. Dent Mater. 2008;24:778-85.

24- Marchesi G, Breschi L, Antoniolli F, Di Lenarda R, Ferracane J, Cadenaro M. Contraction stress of low-shrinkage composite materials assessed with different testing systems. Dent Mater. 2010;26:947-53.

25- Mills RW, Uhl A, Jandt KD. Optical power outputs, spectra and dental composite depths of cure, obtained with blue light emitting diode (LED) and halogen light curing units (LCUs). $\mathrm{Br}$ Dent J. 2002;193:459-63.

26- Moraes LG, Rocha RS, Menegazzo LM, Araújo EB, Yukimito $\mathrm{K}$, Moraes JC. Infrared spectroscopy: a tool for determination of the degree of conversion in dental composites. J Appl Oral Sci. $2008 ; 16: 145-9$.

27- Oréfice RL, Discacciati JAC, Neves AD, Mansur HS, Jansen WC. In situ evaluation of polymerization kinetics and corresponding evolution of the mechanical properties of dental composites. Polymer Test. 2003;22:77-81.

28- Pianelli C, Devaux J, Bebelman S, Leloup G. The microRaman spectroscopy, a useful tool to determine the degree of conversion of light-activated composite resins. J Biomed Mater Res. 1999;48:675-81.

29- Ribeiro BC, Boaventura JM, Brito-Gonçalves JD, Rastelli AN, Bagnato VS, Saad JR. Degree of conversion of nanofilled and microhybrid composite resins photo-activated by different generations of LEDs. J Appl Oral Sci. 2012;20:212-7.

30- Scotti N, Venturello A, Migliaretti G, Pera F, Pasqualini D, Geobaldo F, et al. New-generation curing units and short irradiation time: the degree of conversion of microhybrid composite resin. Quint Int. 2011;42:89-95.

31- Tsai PC, Meyers IA, Walsh LJ. Depth of cure and surface microhardness of composite resin cured with blue LED curing lights. Dent Mater. 2004;20:364-9.

32- Truffier-Boutry D, Demoustier-Champagne S, Devaux J, Biebuyck JJ, Mestdagh M, Larbanois P, et al. A physico-chemical explanation of the post-polymerization shrinkage in dental resins. Dent Mater. 2006;22:405-12.

33- Truffier-Boutry D, Gallez XA, Demoustier-Champagne S, Devaux J, Mestdagh M, Champagne B, et al. Identification of free radicals trapped in solid methacrylated resins. J Polymer Sci. 2003;41:1691-9.

34- Van Dijken JW, Pallesen U. Clinical performance of a hybrid composite resin with and without an intermediate layer of flowable composite resin: a 7-year evaluation. Dent Mater. 2011;27:150-6. 